\title{
Significance of Quadruple assessment of breast lump-A hospital based Study
}

\author{
Shrestha $\mathrm{MK}^{1}$, Ghartimagar $\mathrm{D}^{2}$, Ghosh $\mathrm{A}^{2}$,Shrestha $\mathrm{E}^{3}$, Bolar $\mathrm{P}^{3}$ \\ ${ }^{\prime}$ Department of Radiology, Gandaki Medical College,Pokhara, Nepal. \\ ${ }^{2}$ Department of Pathology, Manipal Teaching Hospital, Pokhara, Nepal. \\ ${ }^{3}$ Department of Radiology, Manipal Teaching Hospital, Pokhara, Nepal.
}

\section{Keywords:}

Breast carcinoma; Cytology;

Mammography;

Sonomammography.

\section{ABSTRACT}

Background: Approximately $10 \%$ of breast masses are breast cancer. It is important for women with a breast lump to receive appropriate evaluation. Mammography has been the "gold standard" in breast cancer detection for $>40$ years. Ultrasonography is non-invasive easily available, cheaper and accurate tool while Fine needle aspiration cytology has a high diagnostic accuracy rate in hands of experienced cytopathologist.

Materials and methods: This was a retrospective and prospective study of 173 women attending radiology department in Manipal Teaching Hospital, Pokhara for mammography during a period of 18 months from January 2011 to June 2012.The age ranged from 20yrs to 75yrs. BIRADS score was given for both mammography and sonomammography. All malignant and suspicious cases had undergone fine needle aspiration cytology. Cytology reports were correlated with imaging study.

Results: The most common age group for the breast lump was 40-49 years showing 65(37.57\%) cases. Most lumps were seen on the left side 54.3\% (94/173) cases and were seenin upper outer quadrant of the breast ( 74 cases). 11 cases each were given the BIRADS score of 4 in both mammography and sonomammography. Sensitivity and specificity of mammography and sonomammography were compared to cytologyreports. The sensitivity for mammogram was $73.7 \%$ while specificity was $96.3 \%$. The sensitivity and specificity for sonomammogram was $78.9 \%$ and $95 \%$ respectively.

Conclusion: Quadruple assessment i.e. clinical assessment, mammography, sonomammography and cytologicalstudy are the new "gold standard" in the investigation of breast disease.

\section{INTRODUCTION}

Breast masses are localized swellings that feel different from the surrounding breast tissue. It is a symptom/sign for a variety of conditions. As approximately $10 \%$ of breast masses ultimately lead to a diagnosis of breast cancer, it is important for women with a breast lump to receive

\section{Correspondence:}

Dr. Manish Kiran Shrestha, MD

Assistant Professor

Gandaki Medical College, Department of Radiology, Pokhara, Nepal Email-manishkiran@hotmail.com appropriate evaluation. ${ }^{1}$ Breast cancer, is an important global health problem and is one of the leading causes of cancer mortality among women across the world. ${ }^{2}$ In the last decades there is little increasing of knowledge and development of breast cancer management, which resulted in little decrease of mortality rates from breast cancer., ${ }^{3,4} \mathrm{All}$ women are at risk for developing breast cancer. A woman's chance of developing invasive breast cancer at some time in her life is approximately 1 in $8(12 \%)$. The older a women is, the greater her chances of developing breast cancer., ${ }^{3,4}$ Breast cancer accounts for $6 \%$ of all cancer cases in Nepal. ${ }^{5}$ 
Early detection and treatment is a key to preventing breast cancer from spreading. A confident diagnosis can be made in $95 \%$ of the cases through a combination of clinical examination, imaging (including mammogram and/or sonomammogram) and fine needle aspiration cytology (FNAC). Mammography and sonomammography are the standard imaging techniques for detection and evaluation of breast disease., Mammography has been the "gold standard" in breast cancer screening and detection for more than 40 years. However, mammography is known toa have a certain false-negative rates. According to data from the Breast Cancer Detection Demonstration Project, the false-negative rate of mammography is about $8-10 \%$. Approximately, 1-3\% of women with a clinically suspicious abnormality, a negative mammogram, and a negative sonogram may still have breast cancer. Possible causes for missed breast cancers include dense parenchyma obscuring a lesion, poor positioning or technique, perception error, incorrect interpretation of a suspicious finding, subtle features of malignancy, and slow growth of a lesion. ${ }^{6}$

Sonomammography is non-invasive easily available, cheaper and accurate tool in diagnosing breast masses. It is very helpful in pre surgical assessment of tumor size of even $2 \mathrm{~mm} .^{7}$ It is the method of choice for differentiating solid from the cystic lesions, for further characterizing mammographic findings and better appreciating palpable breast lesions. Increasing confidence with the needle and increasing resolution of ultrasound machines have expanded the scope of ultrasound to guide diagnostic biopsies more accurately and measure tumors. ${ }^{8,9}$ FNAC has a high diagnostic accuracy rate $(97 \%)$ in the hands of experiencedcytopathologists. ${ }^{10}$ FNAC is a reliable method to differentiate whether a suspicious breast mass is benign or malignant from sonomammography and mammography. It helps to confirm the clinical diagnosis without open biopsy. FNAC should be practiced as a routine procedure as there is high degree of correlation with histopathologic findings. FNAC is also an ideal method for patients follow up if there is recurrence of breast lump. ${ }^{11}$

The present study was carried out in an effort to determine and compare the sensitivity of mammogram to sonommamogram for the diagnosis of breast diseases in our set up. The study also shows the trend of breast disease in this western region of country.

\section{MATERIALS AND METHODS}

This was a combined retrospective and prospective study conducted in Manipal Teaching Hospital, Pokhara during a period of 18 months from January 2011 to June 2012. The clinicians obtained a full history, performed breast examination, and then sent the patient for mammography/ sonommamography to the radiology department. Mammography and sonommamography were performed on all cases presented with breast lump. Standard views
Table 1: Age distribution:

\begin{tabular}{ccc}
\hline Age groups & No of cases & Percentage \\
\hline $20-29$ & 31 & $17.91 \%$ \\
$30-39$ & 50 & $28.90 \%$ \\
$40-49$ & 65 & $37.57 \%$ \\
$50-59$ & 19 & $10.98 \%$ \\
$>60$ & 8 & $4.62 \%$ \\
\hline Total & 173 & $100 \%$ \\
\hline
\end{tabular}

Table 2: Distribution of cases according to symptoms

\begin{tabular}{lcl}
\hline Clinical features & No of cases & \% \\
\hline Mastalgia & 60 & $34.68 \%$ \\
Lump & 43 & $24.85 \%$ \\
Mastalgia + lump & 37 & $21.38 \%$ \\
Mastalgia + nipple discharge & 5 & $2.89 \%$ \\
Routine & 9 & $5.20 \%$ \\
Post lumpectomy (benign) & 2 & $1.15 \%$ \\
F/h/o ca. Breast & 5 & $2.89 \%$ \\
Post-op ca. Breast (routine) & 4 & $2.31 \%$ \\
$\begin{array}{l}\text { H/o recurrent breast abscess } \\
\text { (routine) }\end{array}$ & 4 & $2.31 \%$ \\
\end{tabular}

i.e Craniocaudal and Medio-lateral-oblique views of both the breasts were obtained on a dedicated mammography unit (3000 Nova, Mammomat/Siemens) which was subsequently seen by the radiologists. Additional views or spot compression views were obtained where appropriate. Mammograms were interpreted according to the Breast Imaging Reporting and Data System (BI-RADS) diagnostic categories, as BI-RADS 0 (incomplete), 1 (negative), 2(benign finding), 3 (probably benign), 4 (suspicious for malignancy), and 5 (highly suggestive of malignancy). Breast density grades were also determined according tothe BI-RADS on a scale of $1-4$, with 4 corresponding to a dense breast, 3 to a heterogeneous breast, 2 to scattered fibro glandular densities and 1 to an almost entirely fatty breast. ${ }^{8}$

This was followed by a whole breast ultrasound. Ultrasound examinations were performed using high-resolution unit(Logiq P3/ GE) with linear array probe centering at 7.5 $\mathrm{MHz}$. The patients were examined in a supine position and turned slightly to the contralateral side with the ipsilateral upper limb extended cephalad and a pillow placed under the ipsilateral shoulder. This position flattened the breast symmetrically onto the chest wall. Both breasts were scanned by commencing in the axilla and utilizing a clockwise, sequential, overlapping radial approach. Whole breast ultrasound was performed and the diagnosis was scored on five-point scale identical to the mammographic BI-RADS categories. ${ }^{12}$ Mammogram or sonomammogram was considered to be positive if the BI-RADS score was 4 or 5 and negative if the score was 1,2 or 3 . 
Table 3: BI-RADS Distribution

\begin{tabular}{lccccc}
\hline & $\begin{array}{c}\text { BIRADS } \\
\text { SCORE }\end{array}$ & $\begin{array}{c}\text { MAMMOGRAM } \\
(\mathbf{N})\end{array}$ & \multicolumn{2}{c}{ USG (N) } \\
\hline \multirow{2}{*}{ NORMAL } & 0 & 14 & 64 & 0 & 46 \\
& 1 & 50 & & 46 & \\
BENIGN & 2 & 80 & \multirow{2}{*}{94} & 90 & 110 \\
LESION & 3 & 14 & & 20 & \\
\multirow{2}{*}{ MALIGNANT } & 4 & 11 & & 11 & \multirow{2}{*}{19} \\
& 5 & 6 & & 8 & \\
\hline & Total & $\mathbf{1 7 5}$ & & $\mathbf{1 7 5}$ \\
\hline
\end{tabular}

Table 4: Distribution of FNAC diagnosis according to age group

\begin{tabular}{lcl}
\hline \multirow{2}{*}{ Age group } & FNAC diagnosis & \\
\cline { 2 - 3 } $20-29$ & $16(19.75 \%)$ & $2(10.52 \%)$ \\
$30-39$ & $20(24.69 \%)$ & $3(15.78 \%)$ \\
$40-49$ & $31(38.27 \%)$ & $11(57.89 \%)$ \\
$50-59$ & $5(6.17 \%)$ & $2(10.52 \%)$ \\
$>60$ & $9(11.11 \%)$ & $1(5.26 \%)$ \\
\hline TOTAL & 81 & 19 \\
\hline
\end{tabular}

Table 5: Correlation between FNAC diagnosis and mammography

\begin{tabular}{clccc}
\hline & & \multicolumn{3}{c}{ FNAC } \\
\cline { 3 - 5 } & & Benign & Malignant & Total \\
\multirow{2}{*}{ MAMMO } & Benign & 78 & 5 & 83 \\
\cline { 2 - 5 } & Malignant & 3 & 14 & 17 \\
\hline \multicolumn{2}{c}{ TOTAL } & $\mathbf{8 1}$ & $\mathbf{1 9}$ & $\mathbf{1 0 0}$ \\
\hline
\end{tabular}

Table 6: Correlation between FNAC diagnosis and sonommamography

\begin{tabular}{clccc}
\hline & & \multicolumn{3}{c}{ FNAC } \\
\cline { 3 - 5 } & & Benign & Malignant & Total \\
\multirow{2}{*}{ MAMMO } & Benign & 77 & 4 & 81 \\
\cline { 2 - 5 } & Malignant & 4 & 15 & 19 \\
\hline \multicolumn{2}{c}{ TOTAL } & $\mathbf{8 1}$ & $\mathbf{1 9}$ & $\mathbf{1 0 0}$ \\
\hline
\end{tabular}

FNAC was performed in all suspicious lesions, which formed the basis for definitive judgment. FNAC was done with or without real time ultrasound guidance depending upon the size and location of the lesion. All slides were stained with MGG stain and PAP stain.

\section{RESULTS}

The study included 173 patients with breast symptoms, who had all undergone clinical breast examination, mammographyand sonommamography. The youngest patient was 20 years of age and the eldest was 75 years.
Maximum number of cases was seen in 40-49 years age group followed by 30-39 years age group as shown in table $1.58 .95 \%$ of cases presented with history of mastalgia while $46.23 \%$ of cases presented with history of lump. Family history of breast carcinoma was seen in $2.89 \%$ of cases. $4.62 \%$ of patients came for routine mammogram (table 2 ).

In this series mammogram showed 25 women with predominantly fatty breasts, 63 women with scattered fibroglandular densities, 58 women with heterogeneously dense breast and 27 women with extremely dense breast. Clinically left breast (94 cases) was more involved than the right breast (69 cases) and bilateral breasts were involved in 10 cases. Most lesions were seen in upper outer quadrant of the breast ( 74 cases). $47 \%$ of lesions were less than $2 \mathrm{~cm}$ in size while $24.2 \%$ of lesions were equal to or more than 2 $\mathrm{cm}$ in size. The largest lesion, $4.7 \mathrm{~cm}$ in size, was a case of medullary carcinoma of breast involving the left upper outer quadrant. The BI-RADS scoring and positivity for patients with breast lump in mammogram and sonommamogram is shown in table 3. In two cases of bilateral breast lump, 2 different BIRADS scoring was given, so a total of 175 cases were scored according to BI-RADS. The 110 benign cases consisted of benign calcification, fibrocystic changes, intramammary lymph node, lipoma, simple cyst, fibroadenoma, inflammatory lesion and axillary nodes. The 19 malignant cases comprised of both in situ and invasive carcinoma.

Table 4 shows the distribution of cases as benign or malignant in different age groups according to cytology reports. The result shows that most of the malignant cases were seen in 40-49 years of age group. Mammogram was not able to pick up malignant lesion in 5 cases while sonommamogram was not able to pick up the lesions in 4 cases. In the malignant breast lesion the density of breast was either scattered fibroglandular or heterogeneously dense breast. Among the 81 benign lesions detected on cytology, mammography was reported as benign in 78 cases while 77 cases were reported as benign on sonommamography. 19 cases were reported as malignant on cytology of which 14 cases were reported as malignant on mammography and 15 cases as malignant on sonommamography. The 4 cases falsely reported as malignant on sonommamography showed fibroadenomas, benign aspirate, previous scar/ benign aspirate and inflammatory lesion on cytology.

Table 5 and 6 shows the sensitivity and specificity of mammography and sonommamography compared to cytology reports. The sensitivity and specificity of mammography in differentiating benign from malignant lesions were $73.7 \%$ and $96.3 \%$ and in sonommamography the sensitivity and specificity were $78.9 \%$ and $95 \%$ respectively.

Benign pattern of calcification was seen in 15 cases while malignant calcification was seen in 7 cases. Of the 
malignant calcifications there were 5 cases of intraductal carcinoma(IDC), a case of medullary carcinoma and one case reported as positive for malignancy and showing nuclear atypia. Lymph nodes were seen in bilateral axilla in 39 cases. Unilateral axillary lymph nodes were seen in 17 cases; comprising of 6 cases of IDC, 3 cases given as positive for malignancy, a case of medullary carcinoma breast, 1 case of ductal carcinoma in situ, 3 cases of breast abscess and 2 case of fibroadenosis.

\section{DISCUSSION}

Other literatures have shown that patients present with breast cancer at an earlier age in Nepal than in western countries. ${ }^{5}$ Our study also shows that most malignant lesions have been detected in 30-50 years age group in this western region of Nepal. The public and professional awareness has led to change in referral patterns of patients with breast symptoms. Most of the patients are in a state of heightened awareness and thus have been referred for specialist opinion and assessment. Our study showed $54.3 \%$ ( 94 out of 173) had left sided breast lump, followed by $39.9 \%$ ( 69 out of 173 ) in right side of breast and most of the lesions were on the upper and outer quadrant.

This correlates well with the study done by Afsar $A B$ et al who reported left breast lesion in $55 \%$ of cases and upper outer quadrant involvement as the commonest site of tumor. ${ }^{13}$ Shumaila $\mathrm{S} \mathrm{M}$ et al in their study have reported mammography to be positive in 66 (90\%), sonomammography to be positive in $68(93 \%)$ in the 73 cases. $^{14}$ Similarly in our study sonomammography was more sensitive than mammography in detection of malignant lesions. Emine D et al did a study on 546 breast lesions with histopathology analysis. ${ }^{15}$ They reported sensitivity according to age for mammogram to be $52.5 \%$ and for ultrasound to be $72.6 \%$, the specificity was $73.9 \%$ and $88.5 \%$ for mammography and ultrasound respectively. Sidharth etal in their study showed that mammogram had sensitivity of $86.8 \%$ and specificity of $98.6 \%$ while Farhat Arsalan etal reported sensitivity of BI-RADS mammogram to be $87.2 \%$ with accuracy being $88 \%$ when compared with histopathological diagnosis. ${ }^{16,17}$ Smallwood JA et al in a retrospective series of 1000 patients undergoing investigation for symptomatic breast disease revealed the mammography to ultrasound sensitivity to be $82 \%$ : $93 \%$ and specificity to be $89 \%: 95 \% .^{18}$ There seems to be a minor variability in determining the sensitivity, specificity for mammography and sonomammogrphy; however these findings correlate well with our study.

Zonderland et al conducted a prospective trial, including 4,811 mammograms with supplementary ultrasonography, sensitivity increased significantly from approximately $83 \%$ to $91 \% .{ }^{19}$ A study by Lister et al illustrated Ultrasound has significantly higher sensitivity than mammography in detecting malignancy among discrete breast masses. ${ }^{20}$
In our study we have correlated mammography and sonomammography findings with FNAC as it is simple, cost-effective and less traumatic method for diagnosing breast lump. Tiwari $\mathrm{M}$ has recorded the sensitivity and specificity of FNAC of breast to be $83.3 \%$ and $100 \%$ respectively. ${ }^{21}$ Reinikainen $\mathrm{H}$ et al demonstrated sensitivity, specificity and accuracy of FNAC for palpable breast lesion to be $92 \%, 83 \%$ and $88 \% .{ }^{22}$ While Sajid HA reported the accuracy of FNAC in diagnosing malignant breast masses to be $93 \% 96.8 \%$ for benign lesions. ${ }^{23}$ Thus FNAC combined with mammogram and sonomammogram can cut down the number of surgical biopsies for benign breast lesions. Though ultrasound maybe regarded as more sensitive in picking up breast lesions, mammography is far superior in detection of different patterns of breast calcifications. Unilateral axillary lymphadenopathy should be considered suspicious (BIRADS-4) unless specific infectious/inflammatory diseases are ruled out. Schwab F et alin hisstudy of 51 patients having suspicious axillary lymph nodes, found 33 to be benign and 18 to be malignant comprising of 11 cases of non-Hodgkin lymphomas, 4 cases of melanoma, 2 cases of metastasis and only 1 cases of invasive lobular breast carcinoma. ${ }^{24}$ So, suspicious lymphnodes of the axilla seen on ultrasound may not indicate occult breast cancer but may show a variety of other malignancies and generalized infectious disease requiring further treatment.

\section{CONCLUSION}

Our results indicate that breast ultrasound is more accurate than mammography in symptomatic women. High quality breast ultrasound after mammography is of great value in diagnostic breast imaging. When clinical signs and symptoms are combined with USG and mammography which when correlated with FNAC findings, diagnostic accuracy is higher. For suspicious lesions, FNAC is required which decrease the number of surgical biopsies. This quadruple assessment i.e. clinical assessment, mammography, sonomammography and cytological study are the new "gold standard" in the investigation of breast disease.

\section{REFERENCES}

1. Linforth R. Breast Lump and Cancer. InnovAiT 2009;2:17-23. doi: 10.1093/innovait/inn150 Crossref

2. American Cancer Society. Detailed Guide: Breast Cancer What Are the Key Statistics for Breast Cancer? ACS Resource. Available in Crossref [Published on May 16, 2008.]

3. Schonberg MA, Ramanan RA, Mc Carthy EP et al. Decision making and counseling around mammography screening for women aged 80 or older. J Gen Intern Med. 2006;21:279-85. Crossref

4. Badgwell BD, Giordano SH, Duan ZZ et al. Mammography before diagnosis among women age years and older with breast cancer. J Clin Oncol.2008;26: 2482-8. Crossref

5. Singh YP, Sayami P. Managament of breast cancer in Nepal. J Nepal Med Assoc 2009;48:252-7.

6. Kopans DB. Negative mammographic and US findings do not help 
exclude breast cancer. Radiology 2002;222:857-8. Crossref

7. Tresserra F, Feu J, Grases PJ, Navarro B, Alegret X, Frenadez CA. Assessment of breast cancer size. Sonographic and pathologic correlation. J Clin Ultrasound 1999;27:485-91. Crossref

8. Shah V, Raju U, Chitale D. False-negative core biopsies of the breast: an analysis of clinical, radiological and pathologic findings in 27 consecutive cases of missed breast cancer. Cancer 2003;9:1824-31. Crossref

9. Madjar H, Ladner H, Sauerbrei W. Preoperative staging of breast cancer by palpation, mammography and high-resolution ultrasound. Ultrasound Obstet Gynecol 2003;3:185-90. Crossref

10. Jussawalla DJ, Natekar MV, Yeole BB. Cancer incidence in Indian Christian. Br J Cancer 1985;51:883-91. Crossref

11. Aslam S, Hameed S, Afzal T et al. Correlation of FNAC and histological diagnosis in the evaluation of breast lumps. JUMDC 2012;3:221

12. BI-RADS committee, D'Oris CJ, editor. Illustrated breast imaging reporting and data system (illustrated BI-RADS). 3rd ed. Reston: American College of Radiology College of Radiology;1998.1-268pp.

13. Afsar AB, Muhammad MG, Muhammed TA, Sikander HG, Zia U. Role of modified triple test scoring system for evaluation of palpable breast masses in women under age 40. APMC 2010;4:128-32.

14. Shumaila SM, Tayyiba A, Safdar AM. Mammographic - Sonographic co-relation in the diagnosis of breast lump. Biomedica 2008;24:14751.

15. Emine D, Suzana M, Halit Y, Arben K. Comparative accuracy of mammography and ultrasound in women with breast symptoms according to age and breast density. Bosn J Basic Med Sci 2009;9:131-6

16. Sidhartha, Thapa B, Singh Y, Sayami P, Khanal U. Mammographic diagnosis of breast carcinoma: An institutional experience. J Nepal Med Assoc 2008;47:62-5.

17. Farhat A, Anis S, Shahid R et al. Sensitivity and specificity of BIRADS scoring system in carcinoma of breast. J Surg Pak 2010;15:3843.
18. Smallwood JA, Guyer P, Dewbury K et al. The accuracy of ultrasound in the diagnosis of breast disease. Ann R Coll Surg Engl 1986;68:1922 .

19. Zonderland HM, Coerkamp EG, Hermans J, et al. Diagnosis of breast cancer. Contribution of US as an adjunct to mammography. Radiology 1999;213:413-22. Crossref

20. Lister D, Evans AJ, Burrell HC, et al. The accuracy of breast ultrasound in the evaluation of clinically benign discrete, symptomatic breast lumps. Clin Radiol 1998;53:490-2. Crossref

21. Tiwari M. Role of fine needle aspiration cytology in diagnosis of breast lumps. Kathmandu Univ Med J 2007;5:215-7.

22. Reinikainen HT, Rissanen TJ, Piippo UK, Paivansalo M.J. Contribution of ultrasonography and fine needle aspiration cytology to the differential diagnosis of palpable solid breast lesions. ACTA Radiologica 1999;40:383-9. Crossref

23. Sajid HA. The value of fine needle aspiration cytology in the diagnosis of palpable solid breast masses. N Iraqi Med 2010;6:11- 5 .

24. Schwab FD, Burger H, Isenschmid M, Kuhn A, Mueller MD, Gunthert AR. Suspicious axillary lymph nodes in patients with unremarkable imaging of the breast. Eur J Obstet Gynecol Reprod Biol 2010;150:88-91. Crossref 